\title{
The role of remnant bone microbiological cultures in managing diabetic foot osteomyelitis
}

\author{
DEVANGI KETANKUMAR MADANI, ${ }^{1}$ MUJAHID AHMAD SAEED, ${ }^{2}$ ALOK TIWARI, ${ }^{3}$ MIRUNA DELIA DAVID ${ }^{4}$
}

\begin{abstract}
Aim: Effective treatment of diabetic foot osteomyelitis can reduce the risk of major amputations. Our primary aim was to compare the yield in cultures from the proximal and distal segments of bone excised intraoperatively and the impact on antibiotic choice and duration.

Methods: Patients with a confirmed diagnosis of osteomyelitis on bone culture results, where both proximal and distal bone segment samples had been collected, were retrospectively reviewed. Microbiological data were examined to identify true pathogens and studied against antimicrobial choice and duration of prescribing.

Results: A total of $\mathbf{4 7}$ forefoot amputation cases were studied. In $89 \%$ of cases, definite or likely pathogens were isolated from the deep tissues cultured. Definite pathogens (Staphylococcus aureus, Group B streptococcus, Group G streptococcus and Streptococcus anginosus) were identified in $32 \%$ of cases; in $73 \%$ of these, definite pathogens were grown in both the proximal and distal bone segments.

Conclusion: Sampling of remnant bone culture can help in reducing the duration of antibiotic treatment in patients ( $27 \%$ of cases in our series) as it is challenging to correctly estimate intraoperatively whether clear surgical margins have been adequately achieved when resecting infected bone.

Br J Diabetes 2021;21:59-61
\end{abstract}

Key words: diabetes mellitus, antibiotics, amputation, osteomyelitis

Foundation Year 1 Doctor, Russells Hall Hospital, Dudley, UK

2 Consultant Physician and Diabetologist, Department of Diabetes Queen Elizabeth Hospital Birmingham, University Hospitals Birmingham NHS Foundation Trust, Birmingham, UK

${ }^{3}$ Consultant Vascular Surgeon, Department of Vascular Surgery, Queen Elizabeth Hospital Birmingham, University Hospitals Birmingham NHS Foundation Trust, Birmingham, UK

${ }^{4}$ Consultant Microbiologist, Department of Clinical Microbiology, Queen Elizabeth Hospital Birmingham, University Hospitals Birmingham NHS Foundation Trust, Birmingham, UK

Address for correspondence: Dr Mujahid Ahmad Saeed Consultant Physician and Diabetologist, Department of Diabetes Queen Elizabeth Hospital Birmingham, University Hospitals Birmingham NHS Foundation Trust, Mindelsohn Way, Edgbaston, Birmingham

B15 2GW, UK

E-mail: mujahid.saeed@uhb.nhs.uk

https://doi.org/10.15277/bjd.2021.285

\section{Introduction}

The increase in the prevalence of diabetes mellitus and its associated complications has become a major public health issue worldwide. ${ }^{1}$ Diabetic foot osteomyelitis (DFO) is a well-recognised complication of diabetes; it is found in $50-60 \%$ of patients hospitalised for a diabetic foot infection and is a risk factor for lower limb loss. 2,3 The bone infection often involves the forefoot and develops by contiguous spread from overlying soft tissue. Many cases of DFO are polymicrobial, with Staphylococcus aureus being the most commonly isolated pathogen. ${ }^{2,3}$ DFO is generally diagnosed by combinations of clinical features, serum inflammatory markers and imaging. The gold standard for laboratory diagnosis includes microbiological and histological examinations; the latter is, however, carried out infrequently in practice. ${ }^{3,4}$

The optimal management of DFO is still a matter of debate and there is no universally accepted strategy. The International Working Group for Diabetic Foot (IWGDF) guidelines on foot infections recommends surgical intervention in cases of DFO accompanied by spreading soft tissue infection, progressive bone destruction on X-ray or bone protruding through the ulcer. They recommend 6 weeks of antibiotic therapy for patients who do not undergo resection of infected bone and no more than 1 week of antibiotic treatment if all infected bone is resected. ${ }^{3}$ This is not universally adopted, with other studies favouring at least 6 weeks of treatment even in cases where bone has been excised, because it is unclear if all the infected bone has been removed. 5,6

Limited data are available regarding the role of microbiological cultures in managing DFO. Previous studies recommend antibiotic treatment directed by culture results and it is accepted that empirical treatment will often be required before cultures are available or if there is no yield in culture. Recommendations from major guidelines on diabetic foot infection and the experience of expert clinicians suggest that a patient with proximal margin bone infection should be further treated with a prolonged course of antibiotic therapy. ${ }^{2,3}$ Evidence supporting the idea that culture from proximal (remnant) bone specimens is of any clinical benefit has to date been restricted only to small studies. ${ }^{4,7,8}$ The best method of obtaining remnant bone samples at the time of amputation is unclear, but usually involves taking a small piece of bone from the remnant bone after the wound has been cleaned with saline and using sterile instruments. Typically, the surgeon estimates the margin between infected and uninfected bone and excises back until he/she thinks they have reached the healthy bone. A fine balance is, however, needed between ensuring 
that enough bone is resected to achieve clear margins and preserving the stability of the foot as well as enough soft tissue remains available for optimum wound healing.

The primary aim of this study was therefore to retrospectively compare the culture results from the proximal and distal segments of bone excised intraoperatively as part of the management of DFO and their impact on antibiotic choice and duration.

\section{Methods}

All patients attending the diabetic foot service at our University Hospital between 1 January 2013 and 31 December 2018 with a radiological confirmation of diagnosis of osteomyelitis were retrospectively selected from the hospital electronic patient hospital records. A database was assembled that included information on each patient's age, gender, date of operation, operation site, the date when the bone segment samples were received in the microbiology laboratory, microorganisms isolated and antibiotics prescribed. Only patients who had both infected bone and remnant bone samples submitted for culture were included.

The bone fragment samples were collected aseptically intraoperatively in the operating theatre and were then transported to the laboratory and processed for Gram stain, culture and antibiotic sensitivity. The microbial isolates identified were then categorised into definite pathogens, likely pathogens and unlikely pathogens based on published literature and generally accepted understanding of the pathogenicity of microorganisms in skin, soft tissue and bone infections. ${ }^{2}$ The choice and duration of antibiotics prescribed were then compared with the hospital prescribing guidelines and microbiologists' recommendations.

\section{Results}

During the study period, a total of 47 patients were included. $83 \%$ of the patients were male with a mean age of 64 years (range 43-94 years). Nineteen (40.4\%) patients had diagnosed peripheral vascular disease requiring intervention, which was angioplasty/stent in 18 (38.3\%) patients and a lower limb bypass in one patient. The median $\mathrm{HbA}_{1 \mathrm{c}}$ was $67.5 \mathrm{mmol} / \mathrm{mol}$ (range 36-110). Thirty-four patients underwent the procedure as an emergency admission. All patients received preoperative antibiotic therapy leading up to the operation. Antibiotics were continued until bone culture results were available. All patients underwent review by physiotherapists and podiatrists for footwear to allow offloading.

The pathogens isolated were then classified into definite pathogens, likely pathogens and unlikely pathogens based on advice from the consultant microbiologist. Classifying these pathogens showed 32\% had grown definite pathogens (in 73\% of these, definite pathogens were grown in both the proximal and distal bone segments), 58\% grew likely pathogens, 4\% grew unlikely pathogens and in $6 \%$ of cases the culture results were negative (Table 1).

The most commonly isolated pathogens from proximal and distal bone segments are shown in Table 2. Mixed anaerobes and Enterococcus faecalis were the most isolated organisms from infected tissues. $11 \%$ of the cases had a major amputation
Table 1 Classification of pathogens cultured from bone samples

\begin{tabular}{ll}
\hline Pathogen classification & Organisms cultured \\
Definite pathogens & $\begin{array}{l}\text { Gram positive cocci: Staphylococcus } \\
\text { aureus, beta-haemolytic streptococci } \\
\text { (such as Group B streptococcus, Group G } \\
\text { streptococcus), Streptococcus anginosus }\end{array}$ \\
Likely pathogens & $\begin{array}{l}\text { Gram negative rods (E. coli, Pseudomonas } \\
\text { aeruginosa, Proteus spp, etc), anaerobes }\end{array}$ \\
Unlikely pathogens & $\begin{array}{l}\text { Enterococci, Coagulase negative } \\
\text { staphylococci }\end{array}$
\end{tabular}

within 12 months of surgery; in $80 \%$ of these cases, surgery was conducted within 2 weeks for sepsis and poor wound healing. In 75\% of this series, beta-haemolytic Group B streptococci and Group G streptococci were isolated and, in the remaining 25\%, organisms which were unlikely to be pathogenic were isolated. In all cases, remnant bone was positive for infection and $80 \%$ of the cases grew probable and/or definite pathogens from both bone segments. In patients who grew definite pathogens, $27 \%$ of the cases had a below the knee amputation within a mean of 10 days while, in patients who grew likely pathogens, $8 \%$ of the cases had a below the knee amputation within a mean of 11 months.

Table 2 Pathogens isolated from bone cultures

\begin{tabular}{|c|c|c|c|}
\hline \multicolumn{2}{|c|}{ Isolated pathogen } & \multicolumn{2}{|c|}{ Bone specimen site $(n=47)$} \\
\hline & & $\begin{array}{l}\text { Proximal (remnant) } \\
\text { bone sample }\end{array}$ & $\begin{array}{l}\text { Distal bone } \\
\text { sample }\end{array}$ \\
\hline \multirow{5}{*}{$\begin{array}{l}\text { Gram } \\
\text { positive } \\
\text { cocci }\end{array}$} & $\begin{array}{l}\text { Coagulase negative } \\
\text { staphylococci }\end{array}$ & $9(19.1)$ & $10(21.3)$ \\
\hline & Staphylococcus aureus & $5(10.6)$ & $6(12.8)$ \\
\hline & Group B streptococcus & $4(8.5)$ & $4(8.5)$ \\
\hline & Group G streptococcus & $3(6.4)$ & 0 \\
\hline & Streptococcus anginosus & $3(6.4)$ & $2(4.3)$ \\
\hline \multirow{14}{*}{$\begin{array}{l}\text { Gram } \\
\text { negative } \\
\text { rods }\end{array}$} & Proteus mirabilis & $8(17)$ & $8(17)$ \\
\hline & Escherichia coli & $6(12.8)$ & $6(12.8)$ \\
\hline & Morganella morganii & $5(10.6)$ & $6(12.8)$ \\
\hline & Pseudomonas aeruginosa & $3(6.4)$ & $4(8.5)$ \\
\hline & Citrobacter freundii & $2(4.3)$ & $3(6.4)$ \\
\hline & Proteus spp. & $2(4.3)$ & $2(4.3)$ \\
\hline & Citrobacter koseri & $2(4.3)$ & $1(2.1)$ \\
\hline & Providencia rettgeri & $1(2.1)$ & $2(4.3)$ \\
\hline & Klebsiella pneumoniae & $1(2.1)$ & $1(2.1)$ \\
\hline & Proteus vulgaris & $1(2.1)$ & 0 \\
\hline & Klebsiella oxytoca & $1(2.1)$ & 0 \\
\hline & $\begin{array}{l}\text { Mixed anaerobes (not } \\
\text { speciated) }\end{array}$ & $5(10.6)$ & $10(21.3)$ \\
\hline & Peptostreptococci & $1(2.1)$ & $1(2.1)$ \\
\hline & Bacteroides fragilis & 0 & $1(2.1)$ \\
\hline \multirow{4}{*}{$\begin{array}{l}\text { Entero- } \\
\text { cocci }\end{array}$} & Enterococcus faecalis & $9(19.1)$ & $10(21.3)$ \\
\hline & Enterococcus spp. & $1(2.1)$ & $2(4.3)$ \\
\hline & $\begin{array}{l}\text { Vancomycin-resistant } \\
\text { Enterococcus }\end{array}$ & $1(2.1)$ & 0 \\
\hline & Enterococcus avium & 0 & $1(2.1)$ \\
\hline
\end{tabular}


Antibiotics were prescribed for a mean of 25 days (range 11-49 days).

\section{Discussion}

DFO can present the clinician with significant therapeutic challenges. Both medical and surgical approaches can be undertaken in the management of DFO, but currently there is no evidence of differences in the effectiveness of various treatment strategies. There is also no strong evidence to inform decisions on the optimal duration of antibiotic therapy. ${ }^{9}$ The recent IWGDF guideline recommends obtaining a specimen of bone tissue at the time of surgery for analysis by culture and histopathology. ${ }^{2}$ In patients who do not undergo complete resection of infected bone the antibiotic therapy should be continued for 6 weeks but, in patients in whom all infected bone has been resected, antibiotic treatment should not be needed for more than 1 week. However, as we have shown in our study, at least $73 \%$ of cases will still need prolonged antibiotics. The National Institute for Health and Care Excellence recommends offering patients antibiotic treatment (usually 6 weeks) according to local protocols. ${ }^{10}$ None of these guidelines specifically addressed the question of interest in the current study - that is, whether there is any benefit in determining if, after surgical resection of apparently infected bone, the clinically uninfected bone is culture positive. The answer to this question would help the clinician in deciding the duration of antibiotic therapy. Some data suggest that, if there is a 'clear margin' (ie, uninfected bone by culture at the site of resection), antibiotic therapy can be safely reduced from several weeks to just days; the rate of clinical cure is also significantly higher than when the margin is culture positive, ${ }^{10}$ which is similar to our results.

In this study we provide evidence that surgical resection of the infected bone is not always enough to achieve complete cure. This high rate of positive culture results demonstrates the challenge in macroscopically evaluating surgical margins. However, there was no established protocol regarding the need to collect a proximal bone specimen and the majority of the samples came from patients being looked after by one of the authors (AT), hence the small numbers, and highlights the variability in practice from those involved in managing these patients. Culture results are also dependent on the sampling method. A positive culture may suggest that not all infected bone has been resected and hence a prolonged course of antibiotics may be needed.

Some results may be falsely positive because of contamination during the biopsy despite precautions taken to avoid this, whilst others may also be false negative because of preoperative antibiotics.

Other studies report increased sensitivity of DNA sequencing compared with conventional microbiological culture techniques. ${ }^{11}$ Our study, however, does add to the current literature as there is a paucity of data on the importance of the role of obtaining microbiological cultures from the remnant bone in managing DFO.

This study shows that it is challenging to always achieve clear surgical margins, thus it is important to collect samples of the remnant bone to help in making a decision regarding the duration of the course of antibiotics. Histopathology may also provide corroborative evidence to help manage DFO, but not much is

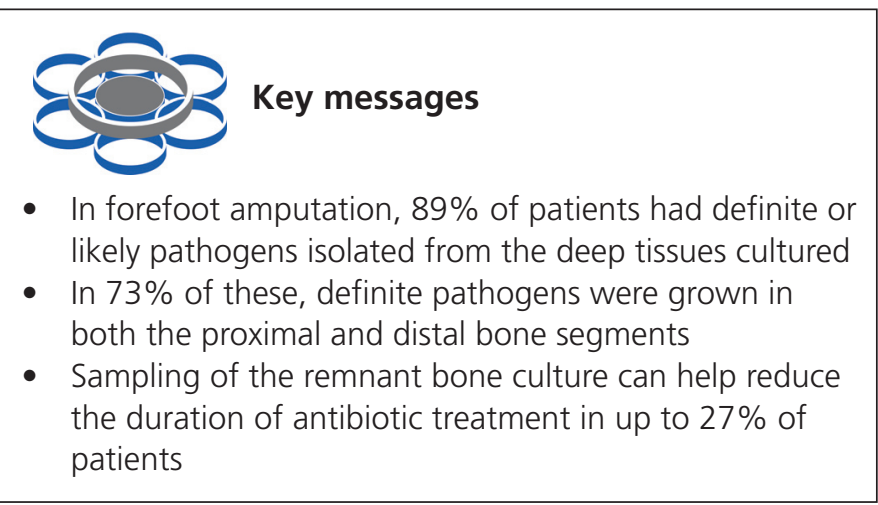

known and further research is needed on the significance and implications on clinical management and of the culture positivity of remnant bone. Protocols should be developed to make this a routine practice so all vascular and diabetic foot teams can implement a policy of bone sampling during forefoot amputations in these patients.

\section{Conflict of interest Nothing to declare. \\ Funding Nothing to declare.}

\section{References}

1. Animaw W, Seyoum Y. Increasing prevalence of diabetes mellitus in a developing country and its related factors. PloS One 2017;12(11):e0187670. https://doi.org/10.1371/journal.pone.0187670

2. Lipsky BA, Senneville E, Abbas ZG, et al. Guidelines on the diagnosis and treatment of foot infection in persons with diabetes (IWGDF 2019 update) Diabetes Metab Res Rev 2020;36(S1):e3280. https://doi.org/10.1002/ dmrr.3280

3. Giurato L, Meloni M, Izzo V, Uccioli L. Osteomyelitis in diabetic foot: a comprehensive overview. World J Diabetes 2017;8(4):135-42. https://dx.doi.org/ 10.4239\%2Fwjd.v8.i4.135

4. Shiraev TP, Lipsky BA, Kwok TMY, Robinson DA. Utility of culturing marginal bone in patients undergoing lower limb amputation for infection. J Foot Ankle Surg 2019;58(5):847-51. https://doi.org/10.1053/j.jfas.2018.12.012

5. Lesens O, Desbiez F, Vidal M, et al. Culture of per-wound bone specimens: a simplified approach for the medical management of diabetic foot osteomyelitis. Clin Microbiol Infect 2011;17(2):285-91. https://doi.org/ 10.1111/j.1469-0691.2010.03194.x

6. Barwell ND, Devers MC, Kennon B, et al. Diabetic foot infection: antibiotic therapy and good practice recommendations. Int J Clin Pract 2017; 71(10):e13006-n/a. https://doi.org/10.1111/ijcp.13006

7. Atway S, Nerone VS, Springer KD, Woodruff DM. Rate of residual osteomyelitis after partial foot amputation in diabetic patients: a standardized method for evaluating bone margins with intraoperative culture. J Foot Ankle Surg 2012;51(6):749-52. https://doi.org/10.1053/j.jfas.2012.06.017

8. Kowalski TJ, Matsuda M, Sorenson MD, Gundrum JD, Agger WA. The effect of residual osteomyelitis at the resection margin in patients with surgically treated diabetic foot infection. J Foot Ankle Surg 2011;50(2):171-5. https://doi.org/10.1177\%2F1938640018770285

9. Berendt AR, Peters EJG, Bakker K, et al. Diabetic foot osteomyelitis: a progress report on diagnosis and a systematic review of treatment. Diabetes Metab Res Rev 2008;24(S1):S145-61. https://doi.org/10.1002/dmrr.836

10. National Institute of Health and Care Excellence (NICE). Diabetic foot problems: prevention and management, 2015. Available at: https://www.nice.org.uk/guidance/ng19/chapter/Recommendations\#diabetic-foot-problems (accessed 27 July 2020).

11. Malone M, Fritz BG, Vickery K, et al. Analysis of proximal bone margins in diabetic foot osteomyelitis by conventional culture, DNA sequencing and microscopy. APMIS 2019;127(10):660-70. https://doi.org/10.1111/ apm. 12986 